\title{
Tendências Metodológicas No Ensino De Matemática: \\ Ciclo De Alfabetização
}

\section{Methodological Trends In Mathematics Teaching: Elementary School}

\author{
Fabrício Monte Freitas \\ Universidade Federal do Rio Grande - (FURG) \\ Elaine Correa Pereira \\ Universidade Federal do Rio Grande - (FURG) \\ Celiane Costa Machado \\ Universidade Federal do Rio Grande - (FURG) \\ João Alberto da Silva \\ Universidade Federal do Rio Grande - (FURG)
}

\begin{abstract}
Resumo
O presente trabalho tem como objetivo fazer um levantamento das principais tendências metodológicas no ensino de Matemática no ciclo de alfabetização do Ensino Fundamental. Para isso buscamos, em periódicos com sua denominação a palavra Matemática. Foram encontrados, de um total de 2591 artigos, 16 que tratavam de alguma tendência metodológica para o ensino de Matemática no ciclo de alfabetização. Para analise dos dados encontrados, utilizamos a análise de conteúdo que serviu para que encontrássemos três categorias de tendências metodológicas: 1) Materiais concretos e Jogos, 2) Modelagem Matemática e Resolução de Problemas e 3) Tecnologias. Além disso, percebemos a influência da formação de professores - inicial ou continuada - no desenvolvimento das tendências. Assim, concluímos que estas se encontram distribuídas de forma homogênea entre as três categorias citadas. Além disso, a formação dos docentes mostrou-se importante para o desenvolvimento das mesmas.
\end{abstract}

Palavras-Chave: Tendências. Matemática. Ciclo de Alfabetização. Anos Iniciais.

\begin{abstract}
The present work has as objective to make a survey of the main methodological tendencies in the teaching of Mathematics in the Elementary School. We searched in brazilian periodicals with the word Mathematics in their name articles about the Elementary School - especially the frist three years- and that had some methodological tendencies for the development of Mathematics teaching. A total of 2591 articles were found, 16 dealing with some methodological tendency for the teaching of Mathematics in the Elementary School. To analyze the data we used the content analysis that served to find three categories of methodological tendencies: 1) Concrete materials and games, 2) Mathematical Modeling and Problem Solving and 3) Technologies. We perceive the influence of teacher training - initial or continuing - in the development of these trends. We conclude that the methodological tendencies of Mathematics in the Elementary School are distributed homogeneously among the three categories mentioned. In addition, the training of teachers has proved to be important for their development.
\end{abstract}

Keywords: Trends. Mathematics. Elementary School. Math Literacy. 


\section{Introdução}

O ensino de Matemática é, costumeiramente, caracterizado por ser de difícil compreensão pelos alunos. Geralmente, o processo de aprendizagem é realizado por meio de práticas tradicionais de ensino que envolve o quadro, o giz, o livro didático e a resolução de exercícios repetitivos e de montar e efetuar continhas. Com base nas atividades desenvolvidas pelo Pacto Nacional pela Alfabetização na Idade Certa - PNAIC, que é um programa que foi desenvolvido no Brasil, foram propostas alterações às práticas docentes nos últimos anos, especialmente no ano de 2014, no qual os(as) professores(as) do ciclo de alfabetização $\left(1^{\circ}\right.$ a $3^{\circ}$ ano do Ensino Fundamental) foram convidados a participar desse programa do Governo Federal para formação continuada. Com isso, entendemos que algumas metodologias puderam ser analisadas e renovadas a partir dessa formação.

O presente trabalho tem como objetivo fazer um levantamento das principais tendências metodológicas no ensino de Matemática no ciclo de alfabetização do Ensino Fundamental. Essas metodologias podem ser compreendidas como as diferentes formas de ensinar Matemática que os(as) professores(as) do ciclo de alfabetização utilizam para abordar as questões matemáticas. Com isso, buscamos compreender quais são as principais atividades utilizadas pelos professores no decorrer dos anos, já que as mais diversas tentativas de projetos do Governo Federal, bem como dos próprios professores, foram lançadas.

Neste artigo, pretendemos elaborar um quadro com as principais tendências metodológicas desenvolvidas pelos professores e pesquisadores na área da Educação Matemática nos Anos Iniciais do Ensino Fundamental, mais especificamente no ciclo de alfabetização. Dessa forma, foram analisados trabalhos das principais revistas científicas da área de ensino com base no Qualis dos periódicos disponibilizado pela Coordenação de Aperfeiçoamento de Pessoal de Nível Superior - CAPES.

Além disso, optamos por trabalhar com revistas brasileiras que dispunham de seu conteúdo de forma digital. Dessa forma, as revistas que não possuem essas prerrogativas foram descartadas. Outro fator relevante de ser destacado é que uma revista, mesmo que indexadas na área de ensino, percebemos que seu conteúdo não se adequava as temáticas pesquisas para esse artigo. 


\section{Metodologia}

Esse trabalho caracteriza-se por ser uma pesquisa de cunho qualitativo, pois entendemos que nossa ideia é compreender as tendências metodológicas que são utilizadas pelos(as) professores(as) do ciclo de alfabetização do Ensino Fundamental, não nos importando com a quantidade de artigos encontrados e, sim, com sua apropriação teórica (GERHARDT; SILVEIRA; 2009). Além disso, a pesquisa trata-se de uma pesquisa bibliográfica do tipo de revisão de literatura (GIL, 2008).

Para iniciarmos o trabalho na busca pelos artigos, primeiramente foi consultada a base de dados da CAPES relacionada à avaliação dos periódicos. Como recorte para esse artigo, foram analisadas as revistas cadastradas na área de ensino, que possuíam qualis A1, A2 ou B1 no último quadriênio, 2013-2016. Além disso, optamos por pesquisar as revistas que possuíam a palavra "Matemática" em seu nome. Outro critério de seleção utilizado para limitar o estudo foi a opção por investigar artigos publicados em língua portuguesa.

A partir dos critérios de seleção adotados, ficamos com um total de 22 revistas científicas, sendo oito com qualis B1, 12 com qualis A2 e duas com qualis A1. Cabe destacar que algumas revistas possuem versões impressas e digitais, fazendo com que os dados sejam duplicados. Dessa forma, chegamos em um corpus de análise de uma revista com qualis A1 (Boletim de Educação Matemática: Bolema), nove revistas com qualis A2 (Acta Scientiae: Revista de Ensino de Ciências e Matemática; Amazônia - Revista de Educação em Ciências e Matemática; Educação Matemática em Revista - SP; Educação Matemática em Revista - RS; Educação Matemática em Pesquisa; Jornal Internacional de Estudos em Educação Matemática; RENCIMA: Revista de Ensino de Ciências e Matemática; REVEMAT: Revista Eletrônica de Educação Matemática; Revista de Educação Ciências e Matemática), já com qualis B1, ficamos com quatro revistas (Boletim Online de Educação Matemática; Em Teia: Revista de Educação Matemática e Tecnológica Ibero-Americana; Perspectivas em Educação Matemática; Revista Brasileira de História da Matemática;).

De punho das revistas a serem analisadas criou-se um banco de dados com todos os artigos publicados nos periódicos a partir do ano de 2011 até setembro de 2017. Esse banco de dados servirá para consultar os títulos que envolvam o ensino de Matemática no ciclo de alfabetização dos Anos Iniciais do Ensino Fundamental e as práticas metodológicas utilizadas pelos professores para ensinarem Matemática nesse ciclo de escolarização.

Optamos por trabalhar com os artigos publicados a partir de 2011 por considerarmos 
importante o levantamento de dados que vem se fazendo atualmente. Pensando assim, o recorte foi realizado para que compreendêssemos as novas tendências metodológicas no ensino de Matemática, em especial nos últimos seis anos.

Em um primeiro momento foram coletados todos os artigos das revistas. Foram consultados os 2591 artigos por meio de uma busca utilizando o "localizar" do editor de planilhas onde foi organizado o banco de dados. A partir disso, foi realizada a busca pela expressão "Anos Iniciais" ${ }^{1 "}$ e colocados na terceira coluna da tabela 1 para serem analisados os títulos com maior atenção. Após a análise dos títulos foram colocados na quarta coluna os artigos que tiveram seu resumo analisado. Passando, então, para a última coluna em que foram lidos os artigos completos. Dessa forma, teremos um corpus de análise de 16 artigos completos. Após a seleção dos títulos que indicavam caracterizar estudos metodológicos no ciclo de alfabetização, foram lidos os resumos destes artigos para compreender se, realmente, eram ligados a tendências metodológicas no ciclo de alfabetização. Quando compreendido que o artigo tratava do assunto em questão, foi lido o artigo completo para que pudéssemos realizar a categorização bem como a analise do artigo.

Tabela 1: Seleção de trabalho para compor o corpus de análise

\begin{tabular}{|l|c|c|c|c|}
\hline \multirow{2}{*}{} & \multirow{2}{*}{ Total de artigos } & \multicolumn{3}{|c|}{ Anos Iniciais } \\
\cline { 3 - 5 } & & Títulos & Resumo & Texto Completo \\
\hline Bolema & 354 & 7 & 4 & 2 \\
\hline Acta Scientiae & 274 & 8 & 3 & 1 \\
\hline Amazonia & 103 & 4 & 1 & 0 \\
\hline Educ.Mat.Rev. & 209 & 9 & 6 & 2 \\
\hline Educ.Mat.Rev.RS & 102 & 4 & 2 & 0 \\
\hline Educ.Mat.Pesq. & 377 & 15 & 6 & 0 \\
\hline Jorn.Int.Est.Ed.Mat. & 112 & 2 & 0 & 0 \\
\hline RENCIMA & 198 & 6 & 0 & 0 \\
\hline REVEMAT & 197 & 8 & 3 & 3 \\
\hline Rev.Ed.Cie.Mat. & 147 & 2 & 2 & 1 \\
\hline BoEM & 48 & 3 & 1 & 1 \\
\hline Em Teia & 131 & 9 & 5 & 3 \\
\hline Persp.Ed.Mat. & 161 & 12 & 4 & 1 \\
\hline Rev.Bra.Hist.Mat. & 85 & 0 & 0 & 0 \\
\hline Rev.PR.Ed.Mat. & 93 & 12 & 4 & 2 \\
\hline Total de Artigos & 2591 & 101 & 41 & 16 \\
\hline
\end{tabular}

Fonte: autoria própria

Para realizar a análise dos artigos publicados nas revistas, nos apropriamos da técnica

\footnotetext{
${ }^{1}$ Foram pesquisadas, posteriormente, as expressões "ciclo" e "anos" isoladamente, mas que não interferiram no resultado dessa pesquisa.
} 
de Análise de Conteúdo (BARDIN, 1977), na qual é realizada uma primeira leitura, onde os textos são agrupados por semelhança de ideias. Logo após, é realizada uma nova leitura, mais atenta, onde, novamente, os artigos são reagrupados formando novas categorias, mais gerais. Assim, as categorias de análise foram construídas com base nas tendências que surgiram nos artigos analisados. Os trabalhos foram agrupados com base na proximidade de suas ações metodológicas. Com isso, foi possível elaborar uma correlação entre os artigos publicados e as principais tendências metodológicas.

\section{Análise Dos Dados}

Com base na leitura e análise dos textos selecionados, podemos elencar três categorias de tendências metodológicas de ensino de Matemática nos ciclo de alfabetização dos Anos Iniciais (1) Materiais Concretos e Jogos; 2) Modelagem Matemática e Resolução de Problemas; 3) Tecnologia). Além disso, optamos por trazer uma quarta categoria de análise formada pelos artigos que, além de mostrarem tendências metodológicas, falavam sobre a formação continuada de professores para o uso dessas metodologias de ensino.

Cabe ressaltar que nas três primeiras categorias cada uma delas teve seis artigos pertencentes a elas - dois artigos estavam em mais de uma categoria ${ }^{2}$. Portanto, optamos por mencioná-las em ordem alfabética. Já a parte que falava sobre a formação de professores possui oito artigos - todos eles estão contemplados em alguma das três categorias de tendências metodológicas, porém trouxeram à tona questões relacionadas à formação continuada dos docentes.

\section{Materiais Concretos E Jogos}

Nossa primeira categoria trata do uso de materiais concretos e dos jogos como ferramenta metodológica para o ensino de Matemática. Optamos por colocar os jogos junto com os materiais concretos por entendermos que para que o jogo seja jogado é necessária à manipulação de materiais concretos, ou, pelo menos, de uma mobilização do pensamento para que resolva a situação proposta, por exemplo, por um jogo de raciocínio lógico. Assim sendo, os jogos são, também, materiais concretos, mesmo que não manipulem manualmente um

\footnotetext{
${ }^{2}$ Entendemos que as categorias devam ser excludentes, porém os artigos tratavam de duas categorias ao mesmo tempo, por exemplo, jogos e tecnologia.
} 
material, mas suas estruturas cognitivas, para o desenvolvimento das atividades propostas pelo professor.

De acordo com Smole, Diniz e Cândido (2007), o jogo traz uma dimensão lúdica ao espaço escolar onde geralmente encontramos apenas o livro didático, o quadro e o giz. Além disso, a possibilidade de aprender por meio dos jogos acontece quando o aluno necessita buscar a solução para determinada ação do jogo, fazendo com que se esforce para encontrar essa solução buscando, então, com que o aluno aprenda algo sobre a atividade que está sendo desenvolvida. Da mesma forma, os materiais concretos fazem com que os alunos ajam sobre o material e esse retribui a ação de forma a fazer o estudante pensar sobre o quê foi realizado, construindo assim, sua aprendizagem.

Nesse sentido, Abrão e Silva (2011), indicam que a utilização dos jogos proporciona interesse e prazer pela disciplina de Matemática, podendo, os jogos, serem distinguidos por jogos de classificação, sequência, simbolização, correspondência e de avaliação. Além disso, quando utilizados são feitos como forma de exercícios de fixação e não como método de ensino que possua a capacidade de estimular o desenvolvimento cognitivo. Existe ainda a possibilidade de avançar na dificuldade dos jogos fazendo com que se tenha mais atenção e reflexão sobre os conhecimentos trabalhados. Este artigo não faz menção se a pesquisa foi realizada com foco no ciclo de alfabetização, porém consideramos na análise por tratar de forma geral o uso dos jogos nos Anos Iniciais do Ensino Fundamental.

Já Pacheco e Pires (2015), trazem referências do uso de materiais por professoras de uma escola estadual de São Paulo, sendo uma de primeiro ano e outra do quinto ano do Ensino Fundamental. Os materiais utilizados pelas professoras são disponibilizados pela Secretaria de Educação Estadual. Na turma de primeiro ano, foco do nosso mapeamento, as autoras citam que a aula proposta pela professora propunha a exploração de um croqui de uma festa onde deveriam ser localizados objetos nessa representação. A professora que aplicou a atividade, segundo as autoras do artigo, não estava totalmente apropriada do material, o quê dificultou sua execução. A professora fala, também, que os materiais servem como norteadores de sua prática já que sente dificuldade em priorizar conteúdos para trabalhar com os alunos.

O artigo de Oliveira e Passos (2013) aponta para a utilização de jogos no ensino de Matemática. O trabalho cita duas possibilidades a serem desenvolvidas com os alunos sendo uma delas um dominó matemático, onde as peças ao se encaixarem devem formar o número 10 por meio da soma dos números de cada peça. Além dessa atividade, propõem, também, o jogo Pegadas Matemáticas que possuí a mesma ideia de um jogo trilha no qual, para avançar as 
casas, é necessário acertar as perguntas e resolver desafios.

Batista e Borba (2016), também trazem a ideia de se desenvolver atividades de jogos com alunos, nesse caso, jogos de (in)dependência de eventos probabilísticos. Para isso, foram propostos jogos que envolviam o lançamento de dados e de moedas. Com isso, os alunos deveriam desenvolver a ideia de independência entre as jogadas em relação aos eventos probabilísticos.

Outro artigo que trata sobre as possibilidades de ensinar probabilidade nos Anos Iniciais, em especial no ciclo de alfabetização é o de Monteiro e Martins (2016). Nele os autores trazem questões vinculadas aos jogos de azar que podem ser trabalhados com as crianças para que se entenda conceitos básicos de probabilidade por meio das atividades desenvolvidas com os jogos.

Campos e Carvalho (2016), também pensam no ensino de probabilidade nos Anos Iniciais. Eles propuseram três atividades com materiais manipulativos, buscando fazer com que as crianças compreendam a probabilidade. As atividades eram chamadas de "Fichas em Sacos", "Sacos com Blocos" e "Clube das Danças". Nas duas primeiras eram colocados itens - fíchas e blocos - em sacos e os alunos tinham que verificar a chance de tirar os itens na sequência determinada pelos autores do trabalho. Já no Clube das Danças a ideia era de ver as possíveis combinações entre os pares de dança ali disponíveis.

Percebemos, então, que a utilização de Materiais Concretos e o desenvolvimento de atividades por meio dos Jogos, visa contribuir para a aprendizagem dos estudantes, em especial do ciclo de alfabetização, por se tratar de crianças que ainda não desenvolveram, por completo, sua capacidade de abstração. Dessa forma, a utilização desses materiais pode auxiliar os professores em sua prática docente.

\section{Modelagem Matemática E Resolução De Problema}

Para Biembengut e Hein (2009) o ensino de Matemática precisa estar voltado para que o conhecimento e as habilidades matemáticas sejam desenvolvidas por meio da resolução de situações que necessitam ser respondidas não bastando, apenas, que o aluno saiba resolver a situação sem que isso seja significativo para ele.

Corroborando com essa ideia, Smole e Diniz (orgs. 2001, p. 88) dizem:

Essa concepção da Resolução de Problemas pode ser vista através de indicações de natureza puramente metodológicas, como usar um problema detonador ou desafio que possam desencadear o ensino e a aprendizagem de conhecimentos matemáticos, trabalhar com problemas abertos, usar a 
problematização ou a formulação de problemas em projetos, etc. Também está presente em orientações mais amplas para o ensino de matemática, que correspondem a linhas de pesquisa e de atuação da Educação Matemática, como é o caso da modelagem e do ensino por projetos.

Indo ao encontro desses autores, optamos por colocar em uma mesma categoria a Resolução de Problemas e a Modelagem Matemática, pois estas surgiram nos trabalhos publicados nas revistas pesquisadas.

Scheller, Bonotto e Viali (2016) buscam desenvolver o pensamento algébrico nos Anos Iniciais por meio da Modelagem Matemática. Para isso, desenvolvem situações-problema que envolvem a Modelagem Matemática com o pensamento algébrico, já que o termo álgebra não é comum nos Anos Iniciais do Ensino Fundamental. Esse trabalho foi desenvolvido com alunos do quarto ano, porém, optamos por trazer ele para discussão por considerar importante o desenvolvimento do pensamento algébrico também no ciclo de alfabetização.

Já Santos, Menezes e Rodrigues (2016), revelam questões de que os livros e materiais didáticos não trabalham a relação da Educação Financeira nos Anos Iniciais do Ensino Fundamental, faz menção apenas em alguns exercícios na forma de cálculo. Além disso, o trabalho traz uma prática de ensino citando coisas que o dinheiro compra e o que o dinheiro não compra. O artigo não faz menção ao adiantamento escolar em que foi aplicado, porém compreendemos que a prática pode ser realizada com qualquer ano escolar fazendo as devidas adaptações.

Oliveira e Passos (2013) utilizam a resolução de problemas como forma de desenvolver as atividades propostas na forma de jogos, já mencionadas na categoria anterior. A resolução de problemas, nesse caso, está ligada a prática dos jogos trabalhados. Nesse sentido, o ato de resolver os problemas de forma correta faria com que os alunos vencessem o jogo em disputa.

Souza e Luna (2014) realizam uma pesquisa em artigos, teses e dissertações que envolvam a Modelagem Matemática nos Anos iniciais. Não à trazem aplicada a alunos, porém é uma importante fonte de dados históricos e que visam propor situações, formações e perspectivas futuras para o ensino de Matemática por intermédio da Modelagem Matemática.

O artigo de Silva e Garnica (2015) é realizado com base na história das Feiras Catarinenses de Matemática. Nele, as autoras discutem questões relacionadas à formação das professoras que mais participaram da feira na categoria dos Anos Iniciais. As professoras que participaram da pesquisa se distinguiam, segundo as autoras, no grupo que "ensinavam a matéria tentando estabelecer conexões com o ensino" (p. 923) e o das professoras que trabalham formando professoras (nos cursos normais), mas que "lecionavam a Matemática usual do $2^{\circ}$ 
grau" (p. 923). Trazem, ainda, que o "ensino de métodos aliados aos materiais e ao conhecimento matemático envolvido, 'o porquê da Matemática, onde se aplica"” (p. 924). Nessa ideia, a interdisciplinaridade, os projetos, o dia-a-dia das crianças envolvido com as atividades desenvolvidas dentro da sala de aula, fazendo com que os alunos, por meio da Modelagem Matemática, consigam compreender melhor os conceitos trabalhados.

Buscando melhorar sua formação e suas práticas, alguns professores participaram de um curso de formação continuada onde discutiam e problematizavam suas próprias práticas com o intuito de melhorar e trocar experiências para um melhor desenvolvimento das atividades que fazem com seus alunos. Essa foi a temática do artigo desenvolvido por Oliveira, Passos e Romanato (2011). Além de terem buscado essa formação, os professores participantes do curso perceberam que trabalhar antes com situações-problemas, e depois com a teoria fazia com que os alunos sentiam-se desafiados a aprender, diferentemente do que, tradicionalmente, realizavam.

Percebemos com a discussão dos artigos aqui mencionados, que a utilização da Resolução de Problemas é considerada como parte da Modelagem Matemática e que podem ser desenvolvidas juntas. Dessa forma, os estudantes podem perceber a utilização da Matemática no desenrolar de sua vida, entendendo sua utilidade e aplicabilidade no dia a dia.

\section{Tecnologia}

No que tange à tecnologia, Kenski (2013) diz que "A rapidez dos avanços tecnológicos repercutiu no crescimento exponencial de novas tecnologias" (p.44) isso nos faz pensar o quanto de tecnologia surge a cada momento e o quanto nós, professores, estamos prontos para absorver todo esse avanço em nossas práticas cotidianas na escola. Moran (2013) vai ao encontro dessa ideia quando diz que "o avanço do mundo digital traz inúmeras possibilidades, ao mesmo tempo em que deixa perplexas as instituições sobre o que manter, o que alterar, o que adotar" (p.11).

Nesse sentido, entendemos que o uso da tecnologia é uma das metodologias que mais deixa os professores com dúvidas de como agir, de como fazer. Porém é, também, uma das formas que mais se busca utilizar para tentar chamar a atenção dos alunos na sala de aula. Assim sendo, fica evidente que seria uma das tendências metodológicas que apareceria em nosso estudo.

Souza e Passos (2015) trazem a discussão do uso do software Superlogo nas aulas dos 
Anos Iniciais, porém a aplicação da ideia se fez com licenciandos em Pedagogia e com professoras dos Anos Iniciais. Estes deveriam aplicar entre si algumas propostas elaboradas por eles utilizando o Superlogo. Dessa forma, entendemos que o artigo não está nos critérios de seleção, porém contribui diretamente para o mapeamento aqui proposto, pois é fundamental compreendermos que a atividade poderia ser incluída nas práticas dos professores desde que tivessem possibilidade de uso nas escolas em que trabalham.

Silva e Scherer (2014) já haviam realizado trabalho parecido com o anterior. Também se tratava de um curso de formação continuada para professores dos Anos Iniciais sobre o uso do software Klogo. Porém, nesse curso os professores deveriam realizar um planejamento e aplicá-lo com suas turmas. Ao realizar a atividades, perceberam que, além do software, é necessário que aconteça uma mudança de postura na prática pedagógica dos professores. O uso da tecnologia por si só não modifica a sala de aula.

Anteriormente ao que foi desenvolvido por Silva e Scherer (2014), Silva (2013) já havia mencionado a formação continuada como uma forma de buscar conhecimentos para desenvolver em sala de aula atividades envolvendo o Klogo. Nesse artigo, Silva (2013), busca identificar como ocorre a (re)construção de conhecimentos sobre quadrados, por uma professora dos Anos Iniciais do Ensino Fundamental, usando o software Klogo.

Leandro, Lima e Lima (2017), buscam introduzir no ensino de Matemática dos Anos Iniciais questões vinculadas a produção de curtas metragem. Para isso, desenvolveram uma oficina sobre o gênero textual roteiro cinematográfico com professores participantes do Pacto Nacional pela Alfabetização na Idade Certa - PNAIC. A ideia da oficina era mobilizar conhecimentos matemáticos para elaboração dos roteiros. O uso das Tecnologias Digitais de Informação e Comunicação - TDIC era fundamental para realização da proposta. Mesmo os professores que não dominavam as ferramentas foram incentivados a buscar o conhecimento para realizar as atividades propostas pela oficina. Dessa forma, a utilização das TDIC pode ter um caráter sedutor para que as crianças busquem o conhecimento matemático a fim de produzirem os roteiros e, posteriormente, os curtas metragem.

Orlovski, Kalinke e Macrosky (2014) fazem uma discussão sobre o programa Um Computador por Aluno - UCA na cidade de Curitiba. No artigo os autores citam que existe uma parceria entre a Prefeitura Municipal e uma Empresa Privada que presta suporte técnico e pedagógico para manutenção do programa. Porém, para realizar essas atividades, a empresa disponibiliza seu próprio material para ser trabalhado pelos professores com os alunos. Além disso, a empresa tem a possibilidade de emitir relatórios com índices de aproveitamento dos 
alunos e, consequentemente, do que foi trabalhado pelo professor. Essas avaliações são balizadas pelos descritores da Provinha Brasil e da Prova Brasil. Para os professores há apenas um deslocamento do que existe no papel - livros didáticos - para o computador. Dessa forma, o computador serve como um estímulo para realização das tarefas. Os exercícios, segundo os autores, são balizados pelo binômio enunciado-resposta, da mesma forma que são utilizados por professores que possuem práticas pedagógicas ditas tradicionais.

Monteiro e Martins (2016) tratam o uso de simuladores e das Tecnologias da Informação e Comunicação - TIC como um facilitador para o aprendizado de probabilidade nos Anos Iniciais do Ensino Fundamental. Entendem, ainda, que o uso de softwares pode fazer com que os alunos sintam mais prazer em aprender e desenvolver suas habilidades vinculadas à probabilidade.

O desenvolvimento das tecnologias pode ser um facilitador para o professor, desde que a escola disponibilize estrutura para isso. Tendo esse recurso, as diferentes abordagens podem ser realizadas em sala de aula. A possibilidade de experienciar as tecnologias na sala de aula pode ser entendida como uma tendência metodológica, desde que o professor mude, também, sua postura frente ao conteúdo a ser desenvolvido, como citado em um dos artigos discutidos. É necessário que não se tenha apenas a transposição do livro didático para o meio digital, pois entendemos que isso seria, apenas, outra forma de trabalhar o conteúdo com as mesmas práticas desenvolvidas tradicionalmente.

\section{Formação Continuada de Professores}

Um importante fator que apareceu nos artigos lidos para esse mapeamento é a importância da formação continuada dos professores e para os professores. Para buscar novas metodologias, novas formas de ensinar os professores, geralmente, buscam cursos de formação continuada o que mostra a incompletude da formação docente em seus cursos de graduação.

Corroborando com isso, Ghedin (2012) já dizia que

\footnotetext{
Não há conhecimento pronto e acabado, do mesmo modo que não há vida absoluta. Tudo é processo contínuo de construção e de autoconstrução. Olhar o que estamos fazendo, refletir sobre os sentidos e os significados do fazer pedagógico é, antes de tudo, um profundo e rigoroso exercícios de compreensão de nosso próprio ser. (p.165)
}

Dentro das categorias já citadas, ficou evidente que boa parte dos artigos discutiu a formação continuada de professores. No que tange as tecnologias aplicadas à sala de aula, percebemos que, usualmente, os professores buscavam novas metodologias para ensinar aos seus alunos por meio do uso de recursos tecnológicos, em especial os computadores. Em um 
dos artigos selecionados, os professores aprenderam a utilizar softwares de criação e edição de vídeos para que, posteriormente, pudessem trabalhar em suas turmas com o recurso da criação de roteiros matemáticos para elaboração de curtas metragens.

$\mathrm{Na}$ categoria de Modelagem Matemática e Resolução de Problemas bem como na categoria de Materiais Concretos e Jogos, podemos perceber que os artigos se entrelaçam, em especial, no compartilhamento de informações e de experiências de sucesso em suas práticas escolares. Eram oferecidos cursos de formação continuada onde os professores poderiam realizar essa troca de ideias, além de construírem novas formas para desenvolverem suas práticas pedagógicas.

Nesse sentido, entendemos que a formação continuada é fundamental para que os professores do ciclo de alfabetização dos Anos Iniciais estejam atentos às novas tendências metodológicas para o ensino de Matemática.

\section{Considerações Finais}

Nosso intuito era de verificar quais as tendências metodológicas mais utilizadas ou que, pelo menos, mais apareciam no ensino de Matemática no ciclo de alfabetização. Percebemos que as revistas científicas que possuem "Matemática" em seu título publicam uma pequena quantidade de textos que vinculem a temática discutida por nós em suas edições, já que de mais de 2500 artigos encontrados, apenas 16 discutem tendências metodológicas no ensino de Matemática do ciclo de alfabetização. Entendemos que, por se tratar de periódicos que não possuem vínculo direto com os Anos Iniciais do Ensino Fundamental, são pouco procurados por profissionais que pesquisam o ensino de Matemática nesse nível de escolarização.

Dos artigos que encontramos, intuímos que as atividades são distribuídas de forma homogênea entre as categorias encontradas: Materiais Concretos e Jogos; Modelagem Matemática e Resolução de Problemas e Tecnologias. Nas três categorias foram encontrados seis artigos que se entrelaçavam em determinados momentos. Ficando de forma explicita a necessidade, por parte dos docentes, de cursos de formação continuada onde estes poderão buscar novas metodologias para o ensino de Matemática.

Dessa forma, compreendemos que tendências metodológicas são as formas que os professores buscam desenvolver seu trabalho de maneira a facilitar a aprendizagem de seus alunos. Assim, buscam inovar ou melhorar suas práticas. Geralmente, quando a formação inicial não é suficiente para que o professor consiga desenvolver alguma tendência metodológica, ele 
busca em cursos de formação continuada subsídios para alargar suas práticas metodológicas.

Entendemos que esse artigo não é um fim em si mesmo, percebemo-lo como um recorte histórico das tendências metodológicas para o ensino de Matemática no ciclo de alfabetização nos Anos Iniciais do Ensino Fundamental. Dessa forma, novas pesquisas se fazem necessárias, com outras bases de dados, para que possamos aprofundar o estudo aqui realizado. Como, por exemplo, revistas que discutam essa temática na área da Educação. Outros bancos de dados, como a Biblioteca Digital de Teses e Dissertações também pode ser consultada para futuras pesquisas, bem como a ampliação do período temporal dessa pesquisa.

\section{Referências}

ABRÃO, Ruhena Kelber; SILVA, João Alberto da. A análise do uso dos jogos para o desenvolvimento do pensamento lógico-matemática nos anos iniciais do Ensino Fundamental. REVEMAT. v. 6, n. 2 , p.67-80, 2011. Disponível em: <https://periodicos.ufsc.br/index.php/revemat/article/view/19811322.2011v6n2p67>. Acesso em: 19 nov. 2017.

BARDIN, Laurence. Análise de Conteúdo. Tradução de Luís Antero Reto e Augusto Pinheiro. Lisboa: Edições, 1977.

BATISTA, Rita; BORBA, Rute. Lançando Dados e Moedas: relação de (in)dependência sob a ótica de crianças dos anos iniciais. Em Teia, v. 7, n. 1, p. 1-20, 2016. Disponível em:

$<$ https://periodicos.ufpe.br/revistas/emteia/article/view/3882>. Acesso em: 19 nov. 2017.

BIEMBENGUT, Maria Salett; HEIN, Nelson. Modelagem Matemática no Ensino. 5. ed. - São Paulo: Contexto, 2009.

CAMPOS, Tânia M. M.; CARVALHO, José Ivanildo Felisberto de. Probabilidade nos anos iniciais da Educação Básica: contribuições de um programa de ensino. Em Teia. v. 7, n. 1, p. 1-18, 2016. Disponível em: $<$ https://periodicos.ufpe.br/revistas/emteia/article/view/3884>. Acesso em: 19 nov. 2017.

GERHARDT, Tatiana Engel; SILVEIRA, Denise Tolfo (orgs). Métodos de Pesquisa. Porto Alegre, Editora da UFRGS, 2009.

GHEDIN, Evandro. Professor Reflexivo: da alienação da técnica à autonomia da crítica. IN: PIMENTA, Selma Garrido; GHEDIN, Evandro. (orgs.). Professor Reflexivo no Brasil: gênese e crítica de um conceito. 7.ed. São Paulo: Cortez, 2012.

GIL, Antonio Carlos. Como elaborar projetos de pesquisa. 4. ed. São Paulo: Atlas, 2008.

KENSKI, Vani Moreira. Tecnologias e tempo docente. Campinas, SP: Papirus, 2013.

LEANDRO, Everaldo Gomes; LIMA, Rodrigo Ferreira; LIMA, Tarcísio de Souza; NASCIMENTO, Lauriza Quina Barreto do. Luz, Câmera, Ação... Quando professores que ensinam Matemática nos anos iniciais criam filmes de curta-metragem. Educação Matemática em Revista, Brasília, v. 22, n. 53, p. 99-108, 2017. Disponível em:

$<$ http://www.sbem.com.br/revista/index.php/emr/article/view/594>. Acesso em: 19 nov. 2017. 
MONTEIRO, Carlos Eduardo Ferreira; MARTINS, Maria Niedja Pereira. Possibilidades de Recursos para o Ensino de Probabilidade nos anos iniciais. Em Teia. v. 7, n. 1, p. 1-20, 2016. Disponível em: $<$ https://periodicos.ufpe.br/revistas/emteia/article/view/5015>. Acesso em: 19 nov. 2017.

MORAN, José Manuel. Ensino e Aprendizagem Inovadores com Apoio de Tecnologias. IN: MORAN, José Manuel, MASETTO, Marcos T.; BEHRENS, Marilda Aparecida. Novas Tecnologias e Mediação Pedagógica. 21.ed. rev. e atual. - Campinas, SP: Papirus, 2013.

OLIVEIRA, Sandra Alves de; PASSOS, Cármen Lúcia Brancaglion. Jogos e Resolução de Problemas na Formação Continuada e em Aulas de Matemática nos anos iniciais. Acta Scientiae, Canoas, RS, v. 15, n. 1, p. 76-92, 2013. Disponível em:

$<$ http://www.periodicos.ulbra.br/index.php/acta/article/view/360>. Acesso em: 19 nov. 2017.

OLIVEIRA, Sandra Alves de; PASSOS, Cármen Lúcia Brancaglion; ROMANATO, Mauro Carlos. Resolução de Problemas em Aulas de Matemática nos anos iniciais: compartilhando experiências da formação continuada e da prática docente. Educação Matemática em Revista. v.16, n. 32, p. 16-27, 2011. Disponível em: <http://www.sbem.com.br/revista/index.php/emr/article/view/203>. Acesso em: 19 nov. 2017.

ORLOVSKI, Nelem; KALINKE, Marco Aurélio; MOCROSKY, Luciane Ferreira. O uso das novas tecnologias: um olhar para a formação do professor que ensina Matemática nos anos iniciais. RPEM, Campo Mourão, PR, v. 3, n. 4, p. 70-88, 2014. Disponível em:

$<$ http://www.fecilcam.br/revista/index.php/rpem/article/view/903>. Acesso em: 19 nov. 2017.

PACHECO, Débora Reis; PIRES, Célia Maria Carolino. Impactos de materiais curriculares na prática do professor que ensina Matemática nos anos iniciais. REVEMAT, Florianópolis, SC, v. 10, n. 2, p. 227-242, 2015. Disponível em: <https://periodicos.ufsc.br/index.php/revemat/article/view/19811322.2015v10n2p227>. Acesso em: 19 nov. 2017.

SANTOS, Barbara Cristina Mathias dos; MENEZES, Adriane Melo de Castro; RODRIGUES, Chang Kuo. Finanças é assunto de criança? Uma proposta de Educação Financeira nos anos iniciais. BoEM, Joinville, v. 4, n. 7, p. 101-115, 2016. Disponível em:

$<$ http://www.revistas.udesc.br/index.php/boem/article/view/8572>. Acesso em: 19 nov. 2017.

SCHERER, Morgana; BONOTTO, Danusa de Lara; VIALI, Lori. Desenvolvimento do Pensamento Algébrico nos anos iniciais por meio da Modelagem Matemática na Educação: possibilidade de utilização da linguagem simbólica. Perspectivas da Educação Matemática. INMA/UFMS. v. 9, n. 21, Seção Temática, p.702-723, 2016. Disponível em:

$<$ http://seer.ufms.br/index.php/pedmat/article/view/2205>. Acesso em: 19 nov. 2017.

SILVA, Luana Quadrini da. O Uso de Laptops e o Software Klogo: um estudo de representações de quadrados por uma professora dos anos iniciais. Revista de Educação, Ciências e Matemática. v. 3, n. 1, p. 40-52, 2013. Disponível em:

<http://publicacoes.unigranrio.edu.br/index.php/recm/article/view/2128>. Acesso em: 19 nov. 2017.

SILVA, Luana Quadrini da; SCHERER, Suely. Formação Continuada de Professores que Ensinam Matemática nos anos iniciais e o Uso de Laptops: reflexões sobre práticas com o Klogo. RPEM, Campo Mourão, PR, v. 3, n. 4, p. 181-202, 2014. Disponível em:

$<$ http://www.fecilcam.br/revista/index.php/rpem/article/view/909>. Acesso em: 19 nov. 2017.

SILVA, Viviane Clotilde da; GARNICA, Antônio Vicente Marafioti. Mostruário de Práticas: considerações sobre a formação e a atuação de professores dos anos iniciais a partir das Feiras Catarinenses de Matemática. Bolema, Rio Claro, SP, v. 29, n. 53, p. 909-935, 2015. Disponível em: $<$ http://www.periodicos.rc.biblioteca.unesp.br/index.php/bolema/article/view/9891>. Acesso em: 19 nov. 2017. 
SMOLE, Kátia Stocco; DINIZ, Maria Ignez; CÂNDIDO, Patrícia. Jogos de Matemática de $\mathbf{1}^{\circ}$ ao $^{\circ}$ ano. Porto Alegre: Artmed, 2007. 152p. (Série Cadernos do Mathema - Ensino Fundamental).

SMOLE, Kátia Stocco; DINIZ, Maria Ignez. (orgs.) Ler, escrever e resolver problemas: habilidades básicas para aprender matemática. Porto Alegre: Artmed, 2001.

SOUZA, Ana Paula Gestoso de; PASSOS, Cármen Lúcia Brancaglion. Dialogando sobre o Planejamento com o SuperLogo no Ensino de Matemática dos anos iniciais. Bolema. Rio Claro (SP), v. 29, n. 53, p. 1023-1042, 2015. Disponível em:

$<$ http://www.periodicos.rc.biblioteca.unesp.br/index.php/bolema/article/view/9868>. Acesso em: 19 nov. 2017.

SOUZA, Elizabeth Gomes; LUNA, Ana Virgínia de Almeida. Modelagem Matemática nos anos iniciais: pesquisas, práticas e formação de professores. REVEMAT, Florianópolis, SC, v.9, Ed. Temática (junho), p. 57-73, 2014. Disponível em:

$<$ https://periodicos.ufsc.br/index.php/revemat/article/view/1981-1322.2014v9nespp57>. Acesso em: 19 nov. 2017. 